\title{
Access to medicines by ambulatory health service users in Mexico: an analysis of the national health surveys 1994 to 2006
}

\author{
Veronika J Wirtz, MFarm, MSc, PhD, (I) Giuliano Russo, BSc, MSc, DrPH, (2) \\ Ma de la Luz Kageyama-Escobar, MC, MPH, DrSc.(I)
}

\begin{abstract}
Wirtz VJ, Russo G, Kageyama-Escobar ML. Access to medicines by ambulatory health service users in Mexico: an analysis of the national health surveys 1994 to 2006. Salud Publica Mex 2010;52:30-38.
\end{abstract}

\begin{abstract}
Objective. To analyse the medicines prescription, prescription filling, payment expenditure for medicines by ambulatory health service users (HSU) in 2006, and to evaluate its evolution in the last 12 years. Material and Methods. Using data from the National Health Surveys in 2006 three binary logistic regression models were constructed to identify the variables associated with the prescription rate, prescription filling and payment for medicines in 2006. The results of access to medicines were compared to the ones from previous National Health Services from 1994 and 2000. Results. The type of health service provider was found to be the most important predictors of access to medicines. Although the proportion of HSU obtaining a prescription and paying for drugs has broadly stayed the same as in 1994, the percentage of HSU paying for their prescribed medicines decreased from $70 \%$ in 1994 to $42 \%$ at Ministry of Health institutions in 2006. Conclusion. The progress in prescription and population access to medicines has been uneven across health service providers.
\end{abstract}

Key words: drugs, access, primary health care, Mexico
Wirtz VJ, Russo G, Kageyama-Escobar ML. Acceso a medicamentos para los usuarios del primer nivel de los servicios de salud: análisis de las encuestas nacionales de salud 1994, 2000 y 2006. Salud Publica Mex 2010;52:30-38.

\section{Resumen}

Objetivo. Analizar la prescripción médica, surtimiento de recetas y gasto en medicamentos que tienen los usuarios del primer nivel de los servicios de salud (UPNS) en 2006 y evaluar su evolución en los últimos 12 años. Material y métodos. Utilizando los datos de la Encuesta Nacional de Salud de 2006 se construyeron tres modelos de regresión logística para identificar los factores asociados con la prescripción, el surtimiento de medicamentos y el pago por medicamentos recetados. Se compararon los resultados del acceso a medicamentos con los de encuestas anteriores de 1994 y 2000 . Resultados. La variable más relevante para el acceso a medicamentos fue el tipo de institución donde se prestó atención. Aunque al nivel global la proporción de los UPNS que obtuvieron una prescripción y que pagaron por los medicamentos más o menos se mantuvo estable, el porcentaje de los UPNS que pagaron por los medicamentos en las instituciones de la Secretaría de Salud disminuyó de 70 a $42 \%$ entre 1994 y 2006. Conclusión. El mejoramiento del acceso a medicamentos para usuarios de los servicios de salud ha sido desigual a través de las instituciones.

Palabras clave: medicamentos, acceso, servicios de salud ambulatorios, México

(I) Instituto Nacional de Salud Pública. Cuernavaca, Morelos, México.

(2) Instituto de Higiene e Medicina Tropical. Lisbon, Portugal.

Received on: October 28, 2008 - Accepted on: September 21, 2009

Address reprint requests to: Ma. de la Luz Kageyama Escobar. Centro de Investigación en Sistemas de Salud, Instituto Nacional de Salud Pública. Av. Universidad 655, col. Santa María Ahuacatitlán. 62100 Cuernavaca, Morelos, México.

E-mail: kescobar@correo.insp.mx 
A ccess to essential medicines in developing countries is one of the indicators of the Millennium Development Goals, and it is considered fundamental to guarantee adequate health care and safeguard human rights. ${ }^{1}$ The World Health Organization (WHO) has defined access as equitable availability and affordability of essential drugs and a key indicator for health care quality and their availability is a pre-requisite to provide effective care. ${ }^{2}$ Access can be measured in various ways; indicators proposed to measure access to medicines include among others prescription rate among health service users (HSU), the ability to obtain the prescribed medicines, percentage of HSU who have to pay for their prescribed medicines and amount of out-of-pocket expenditure on medicines. ${ }^{3}$

In Mexico, like in many other developing countries, access to medicines has been hampered in various ways. ${ }^{4}$ On the one hand, stock-outs of medicines in public healthcare institutions are a chronic problem, in particular in those health services which provide care for the uninsured. ${ }^{5,6}$ This seriously affects quality of care. Pharmaceutical policy in the last decade has focused on improving the availability of medicines in public health care institution. ${ }^{7}$ As a result, a presidential initiative was launched in 2002 to improve logistics and investment in the distribution chain of medicines. ${ }^{8}$ However, since then independent evaluations of the situation of availability of medicines in public healthcare institutions have been of limited scope.

On the other hand, similarly to other developing countries, in Mexico there is a high out-of-pocket expenditure on medicines: a recent OECD report highlights that over $80 \%$ of drugs expenditures are out-of pocket, the highest proportion among the countries considered. ${ }^{9}$ For the lowest income group $60 \%$ of the household expenditure has been attributed to medicines; and $66 \%$ of those health expenditures considered as "impoverishing" - that is, deemed to push consumers below the poverty line-was spent on medicines. ${ }^{10}$ Therefore, providing access to medicines by social security and public health care institutions is considered instrumental to guarantee sustainable access to medicines in the future.

Mexico's health system is fragmented as in many Latin American countries. The main insurers are the one for employed workers (IMSS), the one for employees of governmental institutions (ISSSTE) and the Ministry of Health (Secretaría de Salud - SSA) Institutions for workers from the informal sector or the unemployed. The social security institutions provide prescribed medicines free of charge at the point of care (no co-payment). ${ }^{11}$ To uninsured individuals, the Ministry of Health provides medicines free of charge only for hospitalized patients. Medicines prescribed in ambulatory care (outpatient) are subsidized for uninsured individuals, and fees are inversely related to patients' income. ${ }^{7}$ Whether ambulatory HSU in Ministry of Health facilities are required to pay the fee and the amount paid vary between states.

The structure of the health system has profoundly changed in the last decade. In 2002 a new insurance system, the People's Health Insurance (Seguro Popular), was introduced offering health insurance for all those who were previously uninsured. One of the core objectives of the program is to provide financial protection against catastrophic health care expenditures by provision a basic package of health services free of charge at the point of care. The basic package includes a core set of medicines. Since then more than 10 million individuals have been enrolled, ${ }^{12}$ with the objective to affiliate by 2010 all individuals previously not covered by health insurance, about 50 million in 2002. ${ }^{11}$ Seguro Popular is a purchaser which contracts providers for the delivery of services, mostly Ministry of Health institutions which need to comply with a set of quality criteria in order to qualify as Seguro Popular service providers. As a result in 2006, in most states the Ministry of Health institutions provided care to those without health insurance and those with Seguro Popular, the later with the right to receive a defined list of essential medicines free at the point of care.

In Mexico, National Health Surveys (Encuesta National de Salud/Encuesta National de Salud y Nutricion, ENSA / ENSANUT) have been carried out since 1988 every six years. These are comprehensive surveys consisting of five different questionnaire: household, adults, young people, children and health service use. All of the questionnaires are applied at household level. The majority of questions related to medicines are in the health services use questionnaire and allows analyzing access to medicines for HSU. Comparison of subsequent survey results is feasible, since its core set of questions have not been changed over the years.

In the light of the important changes in health policy in the last decade the objectives of the present research were: 1) to analyse the level of drug prescription, access to and expenditure for prescribed medicines by ambulatory health services users in 2006, and; 2) to evaluate its evolution in the last twelve years.

\section{Material and Methods}

\section{Design and sample size selection}

Data from three national health surveys were used for analysis: the ENSA 1994, 2000 and ENSANUT 2006. 13,14, The surveys consisted of a cross-sectional, multi-stage, stratified random sample of households. 


\section{Data analysis}

On the basis of the WHO definition of access to medicines and the suggested indicators for measuring it, four variables from the National Health Surveys were identified as suitable to analyze access: receiving a prescription, obtaining the prescribed medicines, payment for medicines and finally, expenditure on medicines.

The prescription rate was defined for the three surveys in terms of the proportion of HSU who were prescribed any drug during an outpatient visit. The prescription filling rate was defined as the percentage of HSU with a prescription who were able to acquire the prescribed drugs regardless of payment. Payment for prescribed medicines were defined as the proportion of HSU who reported paying for prescription drugs. Expenditure on medicines made in the consultation was defined as the amount of money spent on the purchased of the prescribed medicines in Mexican pesos reported by HSU. The prescription filling rate was only calculated for 1994 and 2006 surveys due the absence of this variable in the 2000 National Health Survey instrument. Drug expenditures per visit were analysed by their median value. In order to compare 1994, 2000 and 2006 expenditures, constant prices were calculated using a price deflator index with 1993 as a base year, as provided by the Bank of Mexico. ${ }^{15}$ Chi-square and Mann-Whitney tests were performed to check for difference of proportion across group results.

With the information from ENSANUT 2006, multivariate logit models were developed to find the main factors related to prescription, prescription filling and payment for prescribed medicines. The sample weight was used according the design for this analysis. Data were analysed per type of health service provider, patient characteristics and geographical location. Socioeconomic status, regions or ethnicity were of particular relevance to test for inequity in access to medicines. For instance, we were interested in inequity in receiving a prescription due to ethnicity or geographical region after adjusting for clinical factors such as age and disease severity. All the variables included in the models are explained in detail in the following.

\section{Individual characteristics}

Age was included as a categorical variable divided in four groups (0-4,5-14, 15-44, 45 years and older), sex, ethnicity (indicator of indigenous) were included as binary variables.

\section{Household characteristics}

Patients' socio-economic groups were determined on the basis of their annual income and on the ownership of assets such as house, car and other goods. The accessibility to the health facility can be affected by the region where the HSU lives. Five regions were defined according to geographical and political criteria: Northern, Central, Mexico City Metropolitan Area-ZMCM, Southeast-Gulf and areas benefiting of the social assistance programme for disadvantaged areas- PASSPA. * The reason to choose this division by regions was done first, to give tribute to the fact that Mexico has important regional variations with respect to socio-economic development and health service provision. ${ }^{16}$ Previous authors have used similar divisions which makes comparison with data from 1994 possible. $^{17}$

\section{Health care characteristics}

The perception of the severity of the health problem was included in the model categorized as mild, moderate or severe. The type of service provided was also taken into account classified as preventative, curative or other. Curative was used as reference category since it was expected that the prescription was higher in this type of service. The institutions providing care were classified as Social Security, Ministry of Health, those institutions which provide care for Seguro Popular affiliated (which will be called Seguro Popular for the purpose of this study), private providers, other public or private institutions (others).

For the first model, the dependent variable was specified with a value of 1 for being given a prescription and 0 otherwise. The second model had for dependent variable, no or incomplete prescription filling as 1 and 0 if the patient received the prescribed medicines. In the third model the payment for medicines was analyzed giving the value of 1 if the patient had to pay for their medication and 0 otherwise. Results were expressed in

\footnotetext{
* Northern: Baja Califórnia, Baja Califórnia Sur, Sonora, Chihuahua, Sinaloa, Coahuila, Nuevo León, Tamaulipas, Durango and Zacatecas. Central: San Luis Potosí, Guanajauto, Querétaro, Michoacán, México, Tlaxcala, Nayarit, Aguascalientes, Jalisco and Colima. ZMCM: Distrito Federal and metropolitan districts. PASSPA: Hidalgo, Oaxaca, Guerrero and Chiapas. Southeast/ Gulf: Morelos, Puebla, Veracruz, Campeche, Tabasco, Yucatán and Quintana Roo.
} 
terms of adjusted odds ratios with confidence intervals at $95 \%$ level. For the data analysis, the software SPSS version 14 was used.

To evaluate the changes in prescription, prescription filling and expenditure the results from 2006 were compared with the results of the National Health Surveys from 1994 and 2000.

\section{Results}

\section{Prescription and access to medicines in 2006}

\section{Prescription}

In total, 11721 of the 47214 household members interviewed in the 2006 National Health Survey reported having an ambulatory care visit in the last two weeks. Table I describes the frequency of those of who received a prescription, obtained their prescribed medicines and had to pay for them. There was no statistical difference of prescription rates between men and women, indigenous and non-indigenous HSU, or between education levels. Across types of health service providers, private hospitals and clinics as well as PEMEX and military institutions recorded the highest rate of prescription $(>91 \%)$, while in Oportunidades hospitals and National Institutes the rate was approximately $75 \%$.

The percentage of those who were prescribed drugs during an outpatient visit ranged from the lowest 76.5\% in Hidalgo to the highest 93.1\% in Tabasco and Campeche. By geographical regions, patients in the metropolitan area of Mexico City were prescribed drugs $89.9 \%$ of times, while those in the economically disadvantaged PASSPA states were given a prescription in $84.5 \%$ of cases. This latter resulted statistically significant at $p>0.001$.

The results from the logistic regression appear to confirm the general picture from the descriptive statistics, as they identify age, perception of the problem, the type of services and providers the main factors affecting prescription rates in their respective categories (Table II). For those seeking care in private health service providers, the odds ratio of receiving a prescription resulted almost twice as high as for those in the social security as reference category. The prescription rate was higher in Seguro Popular health service providers than in social security ones, meanwhile the lowest rate was found in the Ministry of Health service providers. Lower ages and curative services were the characteristics associated with receiving a prescription more frequently.
Prescription filling

In terms of prescription filling, the overall proportion of patients who were prescribed and obtained their drugs was $95 \%$, while $5 \%$ could only obtain some of the drugs or none at all. Only the health service provider was associated with prescription filling. Most importantly, users of Seguro Popular services were three times less able to obtain all the prescribed drugs $(\mathrm{p}=0.00 ; \mathrm{OR}=3.61$; $95 \% \mathrm{CI}=2.31-5.62)$ and users of Ministry of Health services more than twice less likely $(\mathrm{p}=0.00 ; \mathrm{OR}=2.25$; 95\% CI $=1.39-3.65)$ compared to HSU of social security institutions.

\section{Payment}

As for the proportion of HSU paying for medicines, about $47 \%$ of the patients surveyed reported paying for their prescribed drugs. Patients in PASSPA and Mexico City reported paying more frequently than others (55 and 58\% respectively). Michoacan was the state where the highest percentage of HSU paying for their drugs $(68 \%)$. The logistic regression model shows that the health service provider was one of the strongest predictor of payment (Table III). While social security services recorded by far the lowest probability of paying medicines, users of private health service providers paid frequently for their medicines. A large difference was detected between the odds ratio of the social security institutions, Seguro Popular and those of the Ministry of Health: the odds ratio for Seguro Popular was 4.8 times higher and 9 times higher for the Ministry of Health in comparison to the Social Security. Furthermore, more HSU who perceived their health problem as severe, who were younger and did not have medical insurance happened to pay for their medicines.

Median drug expenditure per visit was \$MX200, although for those patients in the highest socio-economic group it was $\$ M X 300$. Expenditures in Oportunidades health service facilities was the lowest (\$121), and in PEMEX and State ISSSTE was the highest (\$MX 360 and 450). However, when adjusted by perception of the severity of the health problem it becomes apparent that HSU who perceived their problems as severe and visited private health service providers paid significantly more than the ones who visited Ministry of Health, Seguro Popular or other services (Figure 1). Median expenditure for medicines by Seguro Popular users was higher than compared to users of Ministry of Health facilities (\$129 versus $\$ 170$ for mild to moderate health problems and 
Table I

Descriptive statistics ENSANUT 2006

\begin{tabular}{|c|c|c|c|c|c|}
\hline \multicolumn{2}{|c|}{ Variables } & $\begin{array}{c}\text { Frequency (\%) } \\
n=\mid I, 721\end{array}$ & $\begin{array}{c}\text { Percentage }(\%) \text { of HSU } \\
\text { who received a prescrip- } \\
\text { tion } n=10,285\end{array}$ & $\begin{array}{l}\text { Percentage (\%) of HSU } \\
\text { who received their prescri- } \\
\text { bed medicines } n=9,786\end{array}$ & $\begin{array}{l}\text { Percentage (\%) of HSU } \\
\text { who had to pay for their } \\
\text { medicines } n=4,65 \text { I }\end{array}$ \\
\hline \multirow{2}{*}{ Sex } & Male & 4551 (38.8) & 39.4 & 39.4 & 41.4 \\
\hline & Female & 7170 (61.2) & 60.6 & 60.6 & 58.6 \\
\hline \multirow{4}{*}{ Age } & $<5$ years & I 864 (I5.9) & 16.0 & 16.1 & 20.3 \\
\hline & $5-14$ & I 937 (16.5) & 17.1 & 17.1 & 18.4 \\
\hline & $15-44$ & $3613(30.8)$ & 29.7 & 29.5 & 30.5 \\
\hline & $>45$ & 4307 (36.7) & 37.2 & 37.3 & 30. \\
\hline \multirow{4}{*}{ Educational level } & Without education & I 064 (9.1) & 10.9 & 11.0 & II.0) \\
\hline & Primary & $5195(44.3)$ & 53.6 & 53.7 & 52. \\
\hline & Secondary & I $798(15.3)$ & 17.9 & 17.8 & 17.9 \\
\hline & More than secondary & I 779 (I5.2) & 17.5 & 17.5 & 18.2 \\
\hline \multirow{3}{*}{ Indigenous } & Yes & $2249(19.2)$ & 19.1 & 19.1 & 18.5 \\
\hline & No & $9427(80.4)$ & 80.6 & 80.6 & 81.2 \\
\hline & Without information & $45(0.4)$ & 0.3 & 0.3 & 0.3 \\
\hline \multirow{4}{*}{ Socio-economic level } & Very low & $4716(40.2)$ & 40.3 & 40.1 & 39.2 \\
\hline & Low & $2437(20.8)$ & 20.8 & 20.8 & 20.9 \\
\hline & Medium & $3295(28.1)$ & 28.4 & 28.5 & 28.5 \\
\hline & High & I $272(10.9)$ & 10.5 & 10.6 & 11.5 \\
\hline \multirow{2}{*}{ Medical insurance } & Yes & $7160(61.1)$ & 60.9 & 60.6 & 42.1 \\
\hline & No & $4553(38.8)$ & 39.1 & 39.4 & 57.9 \\
\hline \multirow{3}{*}{ Type of service } & Curative & $8170(69.7)$ & 74.0 & 74.3 & 75.1 \\
\hline & Preventive & I $002(8.5)$ & 5.4 & 5.3 & 3.6 \\
\hline & Other & $2546(21.7)$ & 20.6 & 20.3 & 21.3 \\
\hline \multirow{6}{*}{ Institution } & Social Security & $3523(30.1)$ & 30.1 & 30.4 & 4.4 \\
\hline & Ministry of Health & $2785(23.2)$ & 22.1 & 21.5 & 19.5 \\
\hline & Seguro Popular & $1080(9.2)$ & 9.4 & 8.9 & 4.3 \\
\hline & Other public & $37 I(3.2)$ & 2.9 & 2.8 & 2.6 \\
\hline & Private & $3627(30.9)$ & 33.3 & 34.3 & 65.6 \\
\hline & Others & $244(2.1)$ & 2.2 & 2.2 & 3.5 \\
\hline \multirow{5}{*}{ Region } & PASPA & I 374 (II.7) & 11.6 & 11.6 & 13.7 \\
\hline & North & $3317(28.3)$ & 27.9 & 27.9 & 23.6 \\
\hline & Center & $4116(35.1)$ & 35.0 & 34.9 & 36.3 \\
\hline & Metropolitan Zone & $410(3.5)$ & 3.6 & 3.6 & 4.4 \\
\hline & Southeast/Golf & $2504(21.4)$ & 21.9 & 22.1 & 22.0 \\
\hline \multirow{3}{*}{ Perception of the problem } & Mild & $3035(40.2)$ & 40.6 & 40.6 & 38.5 \\
\hline & Moderate & $2585(34.3)$ & 34.5 & 34.4 & 34.5 \\
\hline & Severe & I 921 (25.5) & 24.9 & 25.0 & 27.0 \\
\hline
\end{tabular}

\$200 versus \$290 for severe problems) although not statistically significant.

\section{Evolution of prescription, access and payment}

When comparing data from 2006 with the National Health Surveys conducted in 1994 (HSU=3324) and 2000 (HSU $=53383$ ), prescription rates appear to have steadily increased by approximately 10\% between 1994 and 2006. The proportion of patients who obtained their prescribed medicines did not change significantly. A similar proportion of patients declared paying for their drugs in 1994 and in 2006, about half of those surveyed.

Median drug expenditures per visit went from $\$ 40$ in 1994 to \$200 in 2006. Adjusting for inflation and GDP increase with 1993 prices as base year, median drug expenditures per outpatient visit at constant prices did not appear to change substantially from 1994 to 2006 (Table IV).

However, when breaking down results by health service providers, the proportion of patients who paid 
Table II

FACTORS ASSOCIATED WITH RECEIVING A PRESCRIPTION IN 2006

\begin{tabular}{lcccc} 
& \multicolumn{4}{c}{ Prescription } \\
\cline { 2 - 5 } Variable & p-value & $\begin{array}{c}\text { Odds } \\
\text { ratio }\end{array}$ & $\begin{array}{c}\text { Lower } \\
95 \% \text { IC }\end{array}$ & $\begin{array}{c}\text { Upper } \\
95 \% \text { IC }\end{array}$ \\
Age (years) & & & & \\
$0-<5$ & & & & \\
\hline $5-14$ & 0.655 & $0.88 \mathrm{I}$ & 0.505 & 1.537 \\
\hline $15-44$ & 0.011 & 0.580 & 0.381 & 0.882 \\
\hline 45 and over & 0.018 & 0.599 & 0.392 & 0.917
\end{tabular}

Services

\begin{tabular}{lllll} 
Curative & \multicolumn{5}{c}{} \\
\hline Preventive & 0.000 & 0.282 & 0.161 & 0.494 \\
\hline Other & 0.000 & 0.414 & 0.295 & 0.581
\end{tabular}

Health service provider

\begin{tabular}{lllll} 
Social security & \multicolumn{3}{c}{ I } & \\
\hline Ministry of health & 0.169 & 0.747 & 0.493 & 1.133 \\
\hline Seguro Popular & 0.149 & 1.467 & 0.871 & 2.469 \\
\hline Private & 0.024 & 1.695 & 1.072 & $2.68 \mathrm{I}$ \\
\hline Others & 0.480 & 0.765 & 0.364 & 1.609
\end{tabular}

Source: ENSANUT 2006

The model is adjusted for sex, indigenous, medical insurance, perception of the health problem, socio-economic level, geographical region; $r=0.024$

for their medicines appeared to significantly decrease for Ministry of Health institutions (from 70 to 40\%); for Social Security users the proportion did not change significantly, and the percentage of private providers users slightly increased (Figure 2).

In terms of patients paying for their medicines, in 1994 and 2006 belonging to the poorest PASSPA region was statistically significantly associated with more frequent payment for medicines by HSU; $48 \%$ of HSU in 1994 paid for their prescribed drugs, but such proportion was the highest (59\%) in the PASSPA region and the lowest (38\%) in the Northern states ${ }^{17}$. The difference in proportion of paying patients between 2000 and 2006 appeared particularly stark for the poorest PASSPA regions (50 and 58\% respectively).

As for comparing drugs expenditures across socioeconomic groups, in 1994 approximately $56 \%$ of patients from the highest group but only $45 \%$ from the lowest one received their prescribed drugs free of charge. However, this changed in 2006 where the situation appeared reversed. Less than half $(49 \%)$ of patients from the highest SEC group, but $54 \%$ for those in the lowest income quartile got their prescribed medicines without payment $(p=0.018)$.
Table III

FACTORS ASSOCIATED WITH PAYMENT IN 2006

\begin{tabular}{ccccc} 
& \multicolumn{4}{c}{ Payment for prescribed medicines } \\
\cline { 2 - 5 } Variable & & Odds & Lower & Upper \\
& p-value & ratio & $95 \%$ IC & $95 \%$ IC
\end{tabular}

Age (years)

\begin{tabular}{lllll}
$0-<5$ & \multicolumn{5}{c}{ I } \\
\hline $5-14$ & 0.001 & 0.575 & 0.410 & 0.805 \\
\hline $15-44$ & 0.008 & 0.639 & 0.460 & 0.889 \\
\hline 45 and over & 0.000 & 0.428 & 0.306 & 0.599
\end{tabular}

Perception of severity

\begin{tabular}{lllll} 
Mild & \multicolumn{1}{c}{ I } \\
\hline Moderate & 0.223 & $\mathrm{I} .168$ & 0.910 & $\mathrm{I} .50 \mathrm{I}$ \\
\hline Severe & 0.000 & $\mathrm{I} .697$ & 1.294 & 2.225 \\
\hline Medical insurance & 0.000 & $0.47 \mathrm{I}$ & 0.369 & $0.60 \mathrm{I}$
\end{tabular}

Services

\begin{tabular}{lrrrr} 
Curative & \multicolumn{4}{c}{ I } \\
\hline Preventive & 0.163 & 1.575 & 0.832 & 2.984 \\
\hline Other & 0.000 & 1.789 & 1.355 & 2.364
\end{tabular}

Health service provider

\begin{tabular}{lrrrr} 
Social security & \multicolumn{5}{c}{ I } & & \\
\hline Ministry of Health & 0.000 & 10.705 & 7.252 & 15.803 \\
\hline Seguro Popular & 0.000 & 5.134 & 3.377 & 7.806 \\
\hline Private & 0.000 & 113.648 & 78.713 & 164.087 \\
\hline Others & 0.000 & 20.265 & 13.117 & 31.309 \\
\hline
\end{tabular}

Source ENSANUT 2006; The model is adjusted by sex, indigenous, socioeconomic level, region. $r=0.45$

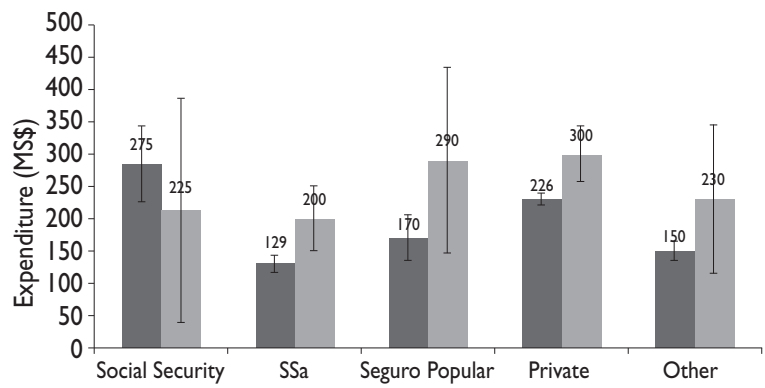

Perception that the health problem is mild to moderate Perception that the health problem is severe $95 \%$ Confidence intervals

Only those health service users who paid for their medicines were included in this analysis.

Source: ENSANUT 2006

Figure I. Median dRUg expenditures Per type of health SERVICE PROVIDER (MX\$) ACCORDING TO THE PERCEPTION OF THE HEALTH PROBLEM IN 2006 
Table IV

COMPARISON BETWEEN PRESCRIPTION, PRESCRIPTION FILLING, PAYMENT AND MEDICINES EXPENDITURE BY HEALTH SERVICE USERS BETWEEN 1994 AND 2006

\begin{tabular}{|c|c|c|c|}
\hline Endpoint & $\begin{array}{c}\text { ENSA } 1994^{*} \\
n=3,324\end{array}$ & $\begin{array}{c}\text { ENSA 2000 } \\
n=53,383\end{array}$ & $\begin{array}{c}\text { ENSANUT } 2006 \S \\
n=\mid I, 721\end{array}$ \\
\hline Proportion of patients with drugs prescribed & $78 \%$ & $81 \%$ & $86 \%$ \\
\hline Proportion of patients who obtained their prescribed drugs & $97 \%$ & NA & $95 \%$ \\
\hline Patients who found all their prescribed drugs in the institution & $61 \%$ & NA & $64 \%$ \\
\hline Proportion of patients who had to buy drugs in private pharmacies & $39 \%$ & NA & $27 \%$ \\
\hline Proportion of patients who paid for their prescribed drugs & $48 \%$ & $42 \%$ & $47 \%$ \\
\hline Median drug expenditure per visit ( $\$ M X$ at current prices) & 40 & 150 & 200 \\
\hline Drug expenditures at constant prices & 37 & 44 & 40 \\
\hline $\begin{aligned} \text { Source: } & * \text { ENSA II } 1994 \\
& \neq \text { ENSA } 2000 \\
& \S \text { ENSANUT } 2006\end{aligned}$ & & & \\
\hline
\end{tabular}

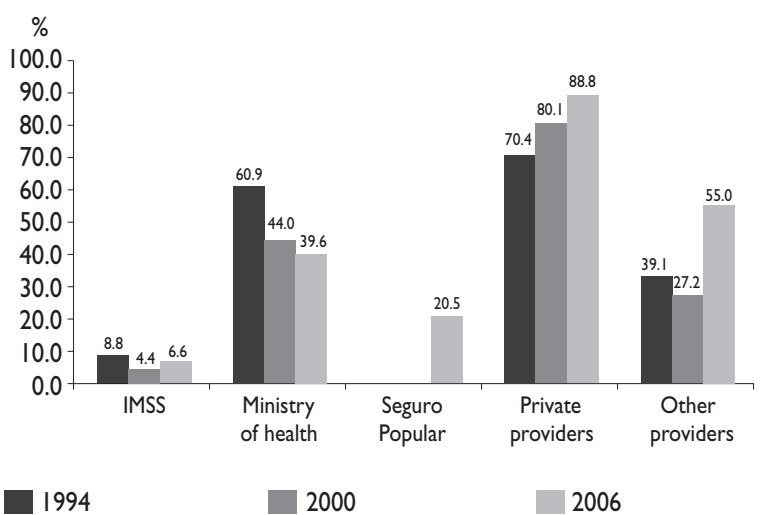

Source: ENSA 1994, ENSA 2000 and ENSANUT 2006

Figure 2. Proportion of health services users paying FOR THEIR MEDICINES BY HEALTH SERVICE PROVIDER

\section{Discussion}

The analysis of the National Health Survey of Mexico provide important data on prescription rate, prescription filling and payment for medicines by ambulatory HSU over the last 12 years which are highly relevant for health policy making.

The results from our analysis showed that type of health service provider is the most relevant predictors of access to drugs for ambulatory HSU in Mexico. It was striking that prescription rates were the highest in private providers and the lowest in Ministry of Health. This should cast doubts on that the prescriptions are purely based on clinical needs, particularly the seemingly high prescription filling rates in the private sector. Our findings appear to be in line with other authors' analysis of the country's health care system's historical evolution, ${ }^{18}$ according to which the system would be highly fragmented and offering diverse quality of care according to the type of health service provider visited.

Overall, population access to medicines did not seem to have improved significantly over the years, as the proportion of HSU obtaining drugs in the institution of care or elsewhere broadly stayed the same as in 1994, just like the proportion of those paying for medicines. However, some reduction in inequality of access indicators was visible in terms of the proportion of patients paying for drugs in the lowest socio-economic groups, although not specifically for the most disadvantaged regions. A possible interpretation of this finding is that change in access to drugs has been driven mostly through selected health service providers, rather than specifically targeting disadvantaged groups. In this way the reduction by nearly half from 70 to $42 \%$ of Ministry of Health services users who had to pay for their prescribed drugs is striking and can be considered an important finding in terms of equity and social protection policy.

In 2006 the median expenditure on medicines varied according to perception of the severity of the health problem. However, in both cases the users of private health service providers had to pay significantly more 
than HSU of other providers. When taking inflation into account, overall median drug expenditures per visit in 2006 appear to have only marginally increased with respect to 1994. Nonetheless when relating such cost to a proxy of the population ability to pay, it emerges that in 1994 the median drug expenditure represented 2.7 times of the daily minimum salary (40 Mexican pesos), but as much as 4.1 times the daily minimum salary (200 Mexican pesos) in 2006. ${ }^{19}$ A possible interpretation of such calculation is that, as nominal prices of medicines increased steadily over the last decade, real wages failed to keep pace; the most affected by such situation are likely to be those on minimum wage, supposedly at the lower end of the income distribution.

Seguro Popular affiliated paid less frequently than other Ministry of Health users. This is an important achievement, taking into account that one of the key objective of this new insurance program is to protect against catastrophic health care expenditure. However, Seguro Popular affiliated more frequently did not obtain some or all of the prescribed medicines and pay more frequently for medicines than their peer users in social security institutions. Furthermore, the median expenditure they spend on medicines appears to be higher than Ministry of Health users which means that Seguro Popular has not achieved fully its objectives. To this respect, further research is required to understand what medicines Seguro Popular patients happen to pay more, in order to evaluate available policy options, such as amplifying the current drug formulary or improving prescribing practice of physicians.

The principal limitation of the data used in our research is that the National Health Surveys only cover access to medicines among ambulatory HSU and not those who do not seek institutional care. In Mexico self-medication is frequent; data from ENSA 2000 show that around one third of individuals (30.5\%) who had a health problem in the last two weeks self-medicated. ${ }^{20}$ In addition, the surveys did not collect information on type of drugs supplied; this made it impossible to analyze prescription patterns and to fully appreciate the extent to which provision of drugs in Mexico has changed over the years. Furthermore, the 2000 ENSA survey did not include questions on the proportion of patient actually obtaining the prescribed drugs in the institutions visited or elsewhere. This latter limited our analysis of the changes of access to drugs over the years.

\section{Conclusions}

Despite the limitations of the data available, the present research contributes in a number of ways to the existing body of knowledge on prescription, prescription filling and payment for medicines in low and middle-income countries. First of all, the study shows that in Mexico the vast majority of HSU receive a prescription, although only half of them free of charge. Secondly, the type of provider is an important predictor of prescription, prescription filling and payment.

Although prescription rates appear to have increased steadily, in terms of payment, the overall situation did not appear to have changed significantly in the last 12 years. However, improvement is visible for users of Ministry of Health and Seguro Popular providers, where the proportion of users paying for medicines has fallen considerably. Given the Government's effort and resources devoted to reducing inequalities in health service utilisation, further evaluation is needed to assess the impact and cost-effectiveness of its action. Without any doubt, understanding better these aspects would help design more effective policies, as well as allocate scarce health resources across those programmes poised to yield the highest value for tax-payers' money.

\section{Acknowledgements}

The authors would like to thank the team of researchers and field workers who designed, collected and processed the data and the National Institute of Public Health to provide access to the data. We also would like to thank Mariana Barraza and Lucero Cahuana who commented on an earlier draft and Yared Santa Ana Tellez for her support with the final revision of the analysis and the manuscript.

\section{References}

I. United National Development Program. Trade for development. Geneva: The Millenium Project, 2007. [Access: 2008 oct.]. Available at: http://www. unmillenniumproject.org/goals/gti.htm

2. World Health Organization. How to develop and implement a national drug policy. 2nd World Health Organization: Geneva: WHO, 2002: 16 3. World Health Organization and Harvard Medical School and Harvard Pilgrim Health. Using indicators to measure country pharmaceutical situations. Fact book on WHO level I and level II monitoring indicators. Geneva: WHO, 2006:35-38.

4. Wirtz V, Reich M, Leyva R, Dreser A. Medicines in Mexico:A systematic review of research on access and use. Salud Publica Mex 2008;50 suppl4:470-479

5. Reséndez C, Garrido F, Gómez-Dantés O. Disponibilidad de medicamentos en el primer nivel de atención de Secretaria de Salud. Salud Publica Mex 2000;42:298-308.

6. Gómez-Dantés O, Garrido-Latorre F,Tirado-Gómez LL, Ramírez D, Macías C.Abasto de medicamentos en unidades del primer nivel de atención de la Secretaría de Salud. Salud Publica Mex 200 I;43:224-232. 7. Comisión Federal Para la Protección contra Riesgos Sanitario (COFEPRIS)-Secretaría de Salud (SSA). Hacia una política farmacéutica integral para México. México, DF: SSA, 2005. 
8. Secretaría de Salud. Satisfacer la demanda de medicamentos en el sector de salud, una iniciativa en progreso. México, DF: SSA, 2004 9. Organization for Economic Co-operation and Development (OECD). OECD Reviews of Health Systems: MEXICO. Paris: OECD, 2005:6I. 10. Nigenda G, Orozco E, Olaiz G. La importancia de medicamentos en el Programa del Seguro Popular. Nigenda G, Knaul FM (ed.). En: Caleidoscopio de la Salud. México, DF: Fundación Mexicana para la Salud, 2003:263-273.

II. Organization for Economic Co-operation and Development (OECD). Health working papers. Pharmaceutical pricing and reimbursement policies in Mexico. Paris: OECD, 2007:61

12. Knaul FM, Frenk J. Health Insurance in Mexico:Achieving universal coverage through structural reform. Health Aff 2005;24: 1467-I476. 13. Sepulveda J,Tapia-Conyer R,Velásquez O,Valdespino JL, OlaizFernandez G, et al. Diseño y metodología de la Encuesta Nacional de Salud 2000. Salud Publica Mex 2007;49 Supl3: S427-S432.

15. Olaiz G, Rivera J, Shamah T, Rojas R,Villapando S, Hernández M, et al. Encuesta Nacional de Salud y Nutrición 2006. Cuernavaca, Mexico: Instituto Nacional de Salud Publica, 2006.

15. Banco de Mexico. Índices de Precios al Consumidor y UDIS CPI5I Inflación Período: Ene 1973 - Sep 2008, Mensual, Sin Unidad, Indices , Base 2Q. Jun. 2002. México. DF: Banco de México, 2008.
16. Lemaresquier T, Santizo R. Informe sobre el desarrollo humano en México. México: Programa de las Naciones Unidas para el Desarrollo (PNUD), 2004.

17. Levya-Flores R, Erviti-Erice J, Kageyama-Escobar ML. Prescripción, acceso y gasto en medicamentos entre usuarios de servicios de salud en México. Salud Publica Mex 1998;40(I): I-8

I8. Barraza-Llorens M, Bertozzi S, Gonzalez-Pier E, Gutierrez,JP. Addressing inequity in health and health care in Mexico. Health Aff 2002;2I(3):47-56.

19. Servicio de Administración Tributaria (SAT). Evolution of the minimum salary in Mexico from 1970 to 2007. [Access: 2008 oct.].Available at: http://www.sat.gob.mx/sitio_internet/asistencia_contribuyente/ informacion_frecuente/salarios_minimos/

20. González-Pier E, González-Hernández A. Regulación saludable del sector farmacéutico. Capitulo X, In: Competencia económica en México. Capítulo X. México: Porrúa/ Comisión Federal de Competencia, 2004: 369-425. 